as to bring them within the range of the crushing forceps; in short, for partial, if not for entire, disintegration. The latter, he thinks, is more likely to happen when layers composed of the urate or oxalate are bound together by phosphatic cement. He also directs particular attention to one of the cases, where a considerable quantity of calcareous matter was removed from the prostatic portion of the urethra by the injectios acting on calculi which were found lodged in that part.

Mr. Solly said that he had used the solution recommended by Dr. Hoskins, and he had found it not so unirritating an application as had been represented. The case in which he had employed this injection was certainly a very aggravated one, for the bladder was much diseased, and the urine contained a quantity of mucus, and of the phosphates. In addition to these circumstances the patient had submit. ted to lithotrity ten times. Nothing but the great sufferings of the patient, and his anxiety to be relieved from them, would have induced him (Mr. Solly) to operate. Previously to operating the bladder was injected by means of the double canula, whth simple water; this produced no inconvenience, but the subsequent injection of the lead solution, for four or five days successively, produced so much irritation that the proceeding was obliged to be dispensed with. Nitric acid, which had always before relieved him, was now injected, and his sufferings were somewhat mitigated. Lithotomy was afterwards performed in the usual way, the man did well, and made a peifect recovery.

Mr. Lloyd knew the patient whose case had been just related. It was altogether a most unfavourable one for the application of the injection. Nothing could be injected into the bladder without producing great irritation. The calculus had been broken up two or three times, but the triple phosphates again concreted, and the urine contained mucus and blood. These circumstances rendered the case a most unfavourable one for the use of the injection of $\mathrm{Dr}$. Hoskins.

Mr. Solly said that the patient had been under his care at the dispensary and hospital for about three months. Mucus was passed with the urine during that time, but no blood. Thrt salculi were extracted by the operation.

Dr. WiLlis alluded to the indefinite results which appeared to have followed the nse of the injection by Dr. Hoskins. The solution did not appear, however, to be without its use, though its beneficial effects seemed to be restricted to its influence on the phosphates. We were still however, left without any chemical solvent for uric acid and other calculi; but even on this head he should not despair, for a Hungarian experimentalist had lately discovered that lithium had a remarkable affinity for uric acid, and that a urate of lithium was quickly formed when it came in con tact with a substance containing uric acid. This might prove a valuable fact in practice. With respect to the operation of lithotrity, this, on its first performance, was vaunted as an infallible proceeding, and one that was never attended with unfortunate results. Experience, how ever, had taught the profession that this operation could be regarded as applicable only to those cases in which the stone was small and the bladder healthy.

Mr. Charles Hawnins had seen a great number of cases, of late years, in which lithotrity had been performed by Si B. Brodie. So far from this proceeding being confiued to the cases mentioned by Dr. Willis, he (Mr. Hawkins) had seen many instances in which the stone was of very lirge size, and the bladder in such a state of disease that lityotomy was considered unadvisable. In one case, in which the urine was loaded with phosphates and mucus, and the patient had been unable to evacuate the bladder for two years without the aid of the catheter, the operation of lithotrity acted like a charm, immediate relief was obtained, and the patient was soon restored to society, although, previous to the operation, he had not left his bed for many months. The phosphatic deposit returned in the urine, a stone formed, and was again removed, successfully, by the operation Small fragments left in the bladder, in patients with enlarged prostate, might become nuclei for the formation of fresh stones. He alluded to the case of a gentleman, nearly seventy years of age, from whom a triple-pho:phate calculus was removed by lithotrity, but in whom the urine still con tinued to contain a quautity of ropy mucus. Nothing like a stone could be detected in the biadder. Nitric acid was now injected into that organ by means of the double gold canula. There was less phosphatic deposit in the urine, and the patient was so much relieved that he returned into the country, The symptoms, however, again returned, and, increasing in severity, the bladder was again sounded, and a stone readily detected. This was removed. Its nucleus was so small a fragment, that he (Mr. Hawkins) had frequently seen much larger ones discharged by the urethra. As to lithotrity, and its value, he had seen sixly cases, during the last few years, and of these scarcely one was unsuccessful. In only one case, indeed, did he recollect a fatal termination, and in this case the patient died before all the fragments were removed from the bladder. He had, within the last three years, seen only two cases in which the operation of lithotrity was contraindicated. In one, the operation was begun, but discontinued, and in both instances the patients died, one from malignant disease of the rectum, and the oth.r had a large oxalate of lime calculus, the most difficult of all forms of stone to be removed by this proceeding, for it usually broke into sharp-edged fragments, which produced excruciating pain in their passage through the urethra. If the solution recommended by Dr. Hoskins could either remove or prevent the secretion of mucus it would prove a most valuable aid in therapeutics.

Mr. BRansBY CoOper considered that the solution of Dr. Hoskins might relieve irritability of the bladder consequent upon the presence of a stone, but that the operation of lithotomy, or lithotrity, must be resorted to to effect a cure. He looked upon lithotrity with a less favourable eye than the last speaker. The latter operation could not be resorted to with propriety in any case in which the bladder could not contain and retain six or eight ounces of fluid during the performance of the operation. The mucous membrane of the bladder might be injured should the fuid escape during the proceeding. Patients suffered less from the calculus of oxalate of lime than from the phosphatic variety, notwithstanding the hardness and gravity of the concretion, but in these cases we should not resort to lithotrity on account of the brittleness of the stone. and the angular forms of its fractured portions. He had operated for lithotomy one hundred and ten times, and he had found that the patients affected with oxalate of lime calculus had made the best and quickest recoveries.

Mr. Charles Hawkins recollected no case in which the careful and gradual injection of the bladder, for five or six weeks, had not enabled that organ to retain suficient fluid to allow of the performance of the operation. The only exception to the rule was in a case of oxalate of lime calculus, in which lithotomy was afterwards performed, and the patient sunk.

\section{MARVELLOUSLY CURIOUS INQUEST.}

To the Editor of THE LANCET.

Sin-Do the following facts require any comment ? I am called to a patient stated to be dead, and find her actually strangled, lying in a bed. I with difficulty remove the ligature from her throat, and bring away with me the instrument of death. As there are some circumstances of a suspicious, though mystified, nature, I give notice to the beadle, but whilst he is expecting the coroner's warrant an inquest (?) is actually being held in a hurried manner. I am not called as a witness; there is no medical evidence, nor any evidence of strangulation produced; and the jury bring in a verdict of "Died from natural decay." For the future, would it be the duty of the medical man who by chance is called in, to save himself the trouble of giving any notice in such cases? Or do inquests held in such a way fulfil the object of their institution?

Such was my position in the case of Mary Anne Barnes, No. 4, Walnut-tree-walk, on whose body Mr. Carter affected to hold an inquest at the Ship public-house on the 5th of this month. Noticing this in your answers to correspondents will oblige, your obedient servant,

Lambeth, June 15th, 1844.

M. K. O'SheA.

** If we had not been acquainted with the writing and signature of our correspondent we should, on reading such a communication as the above, have instantly con- 
sidered that the whole was a wanton fabrication. In publishing the note of Mr. O'Shea we are not unwilling to confess that the statements which have been made are of so extraordinary a description that we know not how to comment upon them. We strongly suspect that the circumstances have been misrepresented to Mr. O'Shea. At all events, the publication of his note will afford the parties concerned an opportunity of giving their own version of the transaction.

\section{CLINICAL LECTURES AT UNIVERSITY COLLEGE HOSPITAL.}

To the Editor of THE LANCET.

Sin,-As a student of University College Hospital, I beg leave to state that there has been no scarcity of medical clinical lectures, there being at least three a week. The surgical clinical lectures have, indeed, been few during the last winter session, owing partly to the extensive practice of Mr. Liston leaving him but little time for hospital duties, and also to Mr. Quain's having been ill during that period.

I have been induced to make these few remarks from reading an article in your Journal signed "A Student," but who does not mention the name of his school.

Clevedon, June, 1844.

AN EX-DrEsser.

\section{MORTALITY TABLE.}

The deaths in the metropolis for the week ending June 15th, were 855. The weekly average of the last five years is 946, of the last five winters 1009 .

Diseases of the lungs ........................... 247

Epidemic and contagious diseases $\ldots \ldots \ldots \ldots \ldots \ldots \ldots \ldots \ldots, 19$

Diseases of the nervous system $\ldots \ldots \ldots \ldots \ldots \ldots \ldots \ldots \ldots$. 136

Dropsy, cancer, and diseases of uncertain seat .......... 89

Diseases of the stomach and other digestive organs ...... 65

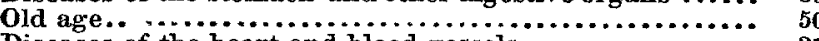

Diseases of the heart and blood ressels ............... 27

Violence, privation, \&c............................. 20

Childbirth and diseases of nterus ......................

Diseases of the kidneys, \&c.

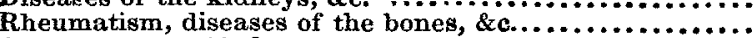

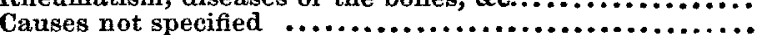

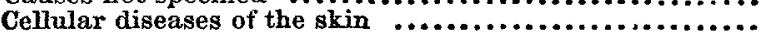

Total............. 85

ROYAL COLLEGE OF SURGEONS OF ENGLAND.

List of gentlemen admitted members on Friday, June 14, 1844 :E. s. F. Arnold, G. Cotton, W. Westall, J. Wiliamson, J. Gould, H. A. Hore, J. D. Cronin, S. T. Badger, E. Garraway, C. W. Blashfield.

\section{APOTHECARIES' HALL, LONDON}

NaMes of gentlemen who obtained certificates of qualification to practise as apothecaries on Thursday, June 13, 1844:- William Culverwell, Christ Church, Surrey; Charles Watkins; William Hammond, Beeston; John Legge Lucas, Northamptonshire; John Lymch, Newbiggin; James Charles Wells, Swaffham, Norfolk Thomas Anthony, Bideford, Devon; Thomas Ledman Henley, Newton, Abbott; Samuel Beecroft, Hyde, Cheshire; Taylor Hannah Murison, Ireland; John Sims Cousins, Walton, Gloucesterghire; Samual Bellon Gwynn, Wem, Salop: Richard Incledon Scott, Falmouth, Cornwall.

\section{CORRESPONDENTS.}

A Lancashire Student will be eligible to examination after eompleting the curriculum specified in his letter, provided he be twenty-one years of age, and shall have completed the term of his apprenticeship.

M.R.C.S.-There can be little doubt that the College will allow gentlemen who have obtained their diplomas to be examined for the fellowship immediately that such examinations are announced. Any other plan would be exceedingly unjust to the existing members of the College.

$M . D$. (Glasgow), has erroneously interpreted the paragraph of our correspondent's letter with which he finds fault. We do not see in it any intended slight of the University of Edinburgh, but merely the enunciation of a fact, viz., that the medical diploma of that university is not recognised by the English poor-law commissioner\$ among the qualifications demanded of the medical officers of poor-law unions.
One who is anxious to investigate by means of the microscope can obtain the article which he requires for about 30l. Powell, Clarendon-street, Somers Town, and Ross, Featherstone-buildings, can be depended upon. A line addressed to either of those gentlemen will obtain particulars. French microscopes are not so good as the English. A very useful instrument, however, may be procured for $10 l$. or $12 l$, exclusive of duty.

The newspaper mentioned by $A$ Dublin Practitioner has not been received.

The case mentioned in the Manchester Guardian shall be duly noticed.

S. L.-The paper was published in the first volume of THE LANCET, 1830-31.

The essay of Mr. Henry Hancock, on dislocation of the astragalus, shall be published as early as possible.

A Lover of Fair Play. - In our review of Dr. Walshe's translation of the second edition of Louis, we openly expressed our regret and surprise that the work had not been entrusted to Dr. Cowan. We have since that inserted a letter from Dr. Cowan himself on the subject. More than this we cannot say.

Humanitas, and several others on the same subject.In the destruction of human life by means of prussic acid, it sometimes happens that in the course of a very few minutes no smell of the poison can be discovered in the room where the death has happened, or even in the mouth of the deceased person.

Communications have been received from Dr. S. Peel, Mr. Aldham, Dr. Cunliffe, Mr. L. Pearson, Mr. Mildmay. A Student (Guy's), A Student (St. Bartholomew's), Mr. J. W. H. Walls, Mr. Warthurton, Mr. Pontifex, Mr. Grossmith, A Subscriber, Dr. Robertson, Mr. Bower Harrison, Mr. J.W.Kipe, Mr. G. Ross, Dr. H.W. Dewhurst, Mr. J. G. Parsons, Dr. Alfred Hall, M.R.C.S, Mr.J.E. Paque, Mr. John Craig, and Dr. Robert Barnes.

Errata.-In The Lancet, June 8th, p. 355, second column, seventeen lines from the bottom, for "origin" read orifice. June 15 th, page 381 , under height of 63 females of "five feet nine inches," read five feet two inches; and in the same page, second column, twentythird line, for the word "s weight" read height.

\section{CONTENTS OF \\ THE BRITISH AND FOREIGN MEDICAK} REVIEW.-NO.XXXY., JULY, 1844.

Part First-A Analytical and Critical Reviews.

Lisfranc's Clinical Surgery. Yol. III-Diseases of the Uterus.

Mr. Wilde's Report on the Causes of Death in Ireland.

Schroeder van der Kolk on Infiammation of the Eye, \&c.

Schroeder van der Kolk on Inflam.
Dr. Hunt on Tic Douloureux, \&c.

Dr. Hunt on Tic Douloureux, \&c.

Mr. Travers on Inflammation and the Healing Process.
Velpeau on the Close Cavities of the Animal Economy.

Williams and Addison on Inflammation and Nutrition.

Dr. Bell on Regimen and Longevity.

Dr. Bell on Regimen and Longevity. Gavin, Marshall, and Fallot on Feigned and $\mathrm{F}$

Stilling, Hannover, and Meyer on the Structure, \&c., of the

Medulla Oblongata.

Dr. Knolz on the Sanitary Condition of Cotton-mills in Austria

Memoirs of the Royal Academy of Medicine.

Quetelet, Laycock, and Schweig on Periodic Vital Phenomena.

Quetelet, Laycock, and Schweig on Periodic Vital Phenomena. Cormack, A

The Vital Statistics of England.

Barras on (iancer of the Stomach, Gastritis, and Gastralgia

Barras on ('ancer of the Stomach, Gastritis, and

Dr. Alison's Pathology and Practice of Medicin

Dr. Armstrong on the Influence of Climate.

Horner on Special Anatomy and

Dr. Grifith on the Microscopical Characters of the Blood, \&c. Dr. Griffth on the

Part Second.-Bibliographical Notices.

Dr. Smith on Scrofula.

Dr. Harrison's correct Theory of the Nerrous System.

Vrolik's Plates of Man and the Mammalia.

Pettigrew on Superstitions of Medicine and Surgery.

Dr. Williams's Prize Essay.

Williams's on the Tongue, in Functional Derangement of the Stomach and Bowels.

Dr. Rees's Pseudo-Second Edition.

Pant ThIRD.-Original Reports and Memoirs.

Dr. Marx on the Influence of Civilisation on Diseases.

Mr. Wharton Jones's Report on the Blood in Inflammation and in the Heuling Process

Memoir of Dr. Barlow.
Books received for Review.

London: John Churchill, Princes-street, Soho. 